\title{
Artificial Intelligence and Collusion
}

\author{
Francisco Beneke • Mark-Oliver Mackenrodt
}

Published online: 20 December 2018

(C) The Author(s) 2018

\begin{abstract}
The debate over whether, in the absence of overt communications, mere tacit coordination between competitors should be outlawed is neither new nor settled. Current technological developments in the field of artificial intelligence (AI) have added further complexity to the discussion, which has given rise to many works that explore the effects of the use of AI-powered pricing software on competition. This paper attempts to contribute to the debate by addressing some issues not covered in previous works. First, there are risks to consumer welfare associated with AI pricing software's capacity to solve uncertainty (for example, supra-competitive equilibria may not be disrupted by changes in demand). Second, the use of artificial neural networks can make detection of anticompetitive pricing patterns more difficult. On the other hand, if authorities can harness the power of the technology themselves, detection problems could be alleviated. Third, the black box argument may not be a problem in this application of artificial neural networks since the pricing software industry has been able to develop more transparent algorithms in response to market demands. Finally, the use of AI pricing software brings some changes to the debate on the feasibility of remedies to mere interdependence, although more work needs to be carried out in this area.
\end{abstract}

Keywords Artificial intelligence - Tacit collusion · Pricing algorithms · Competition law $\cdot$ Oligopoly theory $\cdot$ Concerted practices

\footnotetext{
F. Beneke $(\bowtie)$

LL.M. (Berkeley); Doctoral student, Junior Research Fellow, Max Planck Institute for Innovation and Competition, Munich, Germany

e-mail: francisco.beneke@ip.mpg.de

M.-O. Mackenrodt

Dr. Dr., LL.M. (NYU); Attorney-at-Law (New York); Senior Research Fellow, Max Planck Institute for Innovation and Competition, Munich, Germany

e-mail: mark.oliver@ip.mpg.de
} 


\section{Introduction and Scope of the Paper}

The debate over whether, in the absence of overt communications, mere tacit coordination between competitors should be outlawed is neither new nor settled. Current technological developments in the field of artificial intelligence (AI) have added further complexity to the discussion, which has given rise to many works that explore the effects of the use of AI-powered pricing software on competition. Whereas some commentators argue that the dangers posed by this technology should tip the balance towards making tacit coordination illegal, there are others that are either not entirely persuaded regarding the (future) existence of risks or point out that a rule focusing on mere interdependence is not administrable.

In this paper, we start in Sect. 2 by defining the relevant AI-related concepts in order to understand their relationship with antitrust analysis. In Sect. 3, the law on tacit coordination in the EU is presented as it sets the stage for the debate on which legal changes, if any, are needed to address the problem examined in this paper. In Sect. 4, we provide a concise overview of oligopoly theory as it provides the economic foundation for the regulation of oligopoly pricing. With these main contextual considerations in place, Sect. 5 deals with the substance of this paper, that is, the analysis of whether tacit coordination should be illegal, and if anything changes with the emergence of AI-powered predictive pricing. Other AI implications for antitrust, such as price segmentation, are mentioned only insofar as they relate to interdependent strategies of firms. Our main focus is to establish whether successful price coordination achieved by self-learning algorithms should be punishable under EU competition law and whether the current regulatory framework is sufficient. Section 6 concludes and proposes avenues for future research.

\section{Algorithms and Artificial Intelligence - Relevant Concepts}

As a starting point, the relevant computer science concepts need to be introduced in order to see how they apply to the problem of tacit price coordination. The most foundational concept is that of an algorithm. An algorithm can be defined as a specified sequence of steps for producing a solution to a problem. ${ }^{1}$ Simply put, a computer program or software is a composition of individual algorithms (written in a programming language) that solve specific problems. ${ }^{2}$ A problem should have a fairly general formulation, for example, what are the price and quantity that, holding all else constant, maximizes profit? In this formulation we have three variables price, quantity and profit - that do not have a pre-specified value. These are called parameters. ${ }^{3}$ In addition, as we make more explicit what we mean by "all else constant" we can include more parameters such as the price of competitors and the cost of production.

\footnotetext{
${ }^{1}$ Neapolitan and Naimipour (2010), p. 3.

${ }^{2} I d .$, p. 2.

${ }^{3} I d$., p. 3.
} 
In our example, the algorithm would be the series of steps that have to be taken in order to find the best price according to our profit maximization objective. In our problem, to establish a relationship between price and quantity sold we need to find a demand function in order to be able to calculate price-elasticities. The variables that affect demand are usually numerous. Based on our intuition we can specify a model on how the different variables affect consumers' willingness to pay and, given a data set on the behavior of each variable in the past, we can estimate the model, that is, find the weights of the variables in our specification. Then we can perform a series of tests to determine whether our model has the desired statistical properties and is therefore useful.

When we humans specify models or modify them, we are constrained by the number of relationships we can conceive between different variables. If the number of relevant variables increases, so does the number of combinations and, therefore, the number of candidates for the best model. If new data show that our predictions are not as accurate as we thought, then we need to revise the model and test new candidates.

Artificial intelligence has automated this process. The branch of AI that performs this function is machine learning. In essence, AI powered software adjusts the model automatically according to the data with which it is fed. ${ }^{4}$ Machine learning can be performed through what is called artificial neural networks, which are based on mathematical models of how neurons communicate with each other. ${ }^{5}$ The basic unit in such networks is the "perceptron", which is the digital equivalent of the neuron. Much like a physical neuron, the perceptron receives signals in the form of data, which can come from the outside world or from other perceptrons. These signals, in turn, have different weights according to which they are combined in a single value. That single value is processed within the perceptron through its transfer function. This function then shoots a value, which is then received by other perceptrons to which it is connected. That value is weighted according to the strength of the connection between the perceptrons. And so the process continues until the network produces the specific prediction in which we are interested (for example, a customer segment's willingness to pay or factors associated with increases in revenue). The artificial neural network can adjust the strength of the connections between perceptrons if the model is not good enough, which saves humans the effort of creating and adjusting models. ${ }^{6}$ AI software then shows its greater added value when the variables are too many for the best statisticians to be able to process.

Based on the function of machine learning algorithms and artificial neural networks, Agrawal, Gans and Goldfarb assert that the economic analysis in terms of what this technology can do for business is pretty straightforward. AI-powered

\footnotetext{
${ }^{4}$ Alpaydim (2014), p. 2.

${ }^{5}$ Priddy and Keller (2005), p. 1. The software is inspired on these innerworkings though it is loosely related to how the biological processes work. According to the authors, "artificial neural networks are no more related to real neurons than feathers are related to modern airplanes. Both biological systems, neurons and feathers, serve a useful purpose, but the implementation of the principles involved has resulted in man-made inventions that bear little resemblance to the biological systems that spawned the creative process". Ibid.

${ }^{6}$ Id., pp. 1-8.
} 
algorithms have done nothing more than to decrease the cost of a valuable input: namely, accurate predictions. ${ }^{7}$ While implementation within a firm can be a complex task, on a more abstract level it is fairly easy to see the economic effects, at the firm level, ${ }^{8}$ of a decrease in the cost of an input. For example, complements such as data and the judgment of executives that decide what to do with the prediction or which data to feed into the algorithm - become more valuable. ${ }^{9}$

Another property of the business function of prediction algorithms is that their value is the greatest where uncertainty can significantly affect costs and profits. For the purposes of this paper, we are interested in establishing whether machine learning technology can aid in solving uncertainties that oligopolists need to overcome in order to tacitly establish a price above marginal cost. This analysis is found in Sect. 5.2 below.

\section{Competition Law Treatment of Price Coordination and the Role of Algorithms}

In terms of welfare, coordination with regard to prices is considered as being particularly harmful because prices are one of the most important competition parameters. If the use of algorithms leads to a coordination of prices between different undertakings, Art. 101 of the Treaty on the Functioning of the European Union (TFEU) might apply. This provision does not require that an undertaking possesses market power but that more than one undertaking is involved in the coordination. ${ }^{10}$ By contrast, Art. 102 TFEU requires dominance and can, for example, be applied if an undertaking which possesses market power uses price algorithms for implementing a price discrimination strategy vis-à-vis its customers. Article 101 TFEU prohibits coordination between undertakings and spells out three alternative modes of coordination as being forbidden, namely: "agreements", "decisions by associations of undertakings" and "concerted practices".

The provision seeks to capture joint conduct and, as different kinds of coordination might overlap, a precise characterization of the conduct as belonging to one or to the other alternative of the provision is not required. ${ }^{11}$

The concept of agreement requires an expression or the joint intention of the undertakings to conduct themselves on the market in a specific way ${ }^{12}$ and that there exists a concurrence of will, with the form in which it is manifested being insignificant. ${ }^{13}$ Article 101 TFEU applies to explicit as well as to implicit

\footnotetext{
7 Agrawal, Gans and Goldfarb (2018), p. 13.

${ }^{8}$ The authors admit that when we leave the realm of the firm and enter that of the society as a whole, things get more complicated. See Agrawal, Gans and Goldfarb (2018), p. 210.

${ }^{9} I d$., chapters 5 and 8.

${ }^{10}$ For a general overview of Art. 101 TFEU see, for example, Jones and Sufrin (2016), p. 12.

11 Judgment of 23 November 2006, Asnef-Equifax, C-238/05, EU:C:2006:734, para 31.

12 Judgment of 26 October 2000, Bayer, T-41/96, EU:T:2000:242, para. 67.

13 Judgment of 3 December 2003, Volkswagen, T-208/01, EU:T:2003:326, para. 32; Judgment of 26 October 200, Bayer, T-41/96, EU:T:2000:242, para. 69.
} 
agreements, ${ }^{14}$ and the agreement does not need to constitute a valid contract under national law. ${ }^{15}$

The prohibition of concerted practices seeks to apply to coordination between enterprises which falls short of being qualified as an agreement. ${ }^{16}$ The concept of concerted practice refers to a cooperation which does not reach the level of an agreement but which nevertheless establishes a practical coordination between the undertakings and knowingly substitutes practical cooperation between them for the risks of competition. ${ }^{17}$ Unlike the alternative of an agreement, a concerted practice requires a concertation and a subsequent conduct on the market and (which is presumed) a causal relationship between these two elements. ${ }^{18}$ While for an agreement a mere consensus suffices, it can be inferred from the term "practice" in "concerted practice" that the concertation has to actually be implemented on the market to give effect to the concertation. ${ }^{19}$ However, it is not required that the conduct has resulted in a specific negative effect on competition in the market. ${ }^{20}$

The causal relationship between the concertation and the implementation on the market is presumed. ${ }^{21}$ Therefore, to determine liability it is sufficient to establish the concertation, for example, that an undertaking participated in a meeting where an anti-competitive agreement was concluded or participated in an exchange of such information. The burden of proof then shifts to the undertaking to show that it had no anti-competitive intention and that, for example, it had distanced itself from what was being discussed ${ }^{22}$ or that its subsequent conduct was not influenced by the information which it had received. The concept of concerted action has, for example, been applied to cases of information exchanges and price announcements, ${ }^{23}$ hub and spoke arrangements ${ }^{24}$ and to oligopoly situations. ${ }^{25}$

However, a broad interpretation of the concepts of "agreement" and "concerted practice" does not mean that Art. 101 can be applied as a remedy to all cases where restraints of competition can be observed in a market. Autonomous parallel behavior is not forbidden by Art. 101 TFEU. $^{26}$ A purely unilateral measure without express or tacit acquiescence does not constitute an agreement. ${ }^{27}$ And a mere parallel conduct alone cannot be qualified as a concerted practice. An alternative

\footnotetext{
$\overline{14}$ Jones and Sufrin (2016), p. 141.

15 Judgment of 26 October 2000, Bayer, T-41/96, EU:T:2000:242, para. 67.

16 Jones and Sufrin (2016), p. 153.

17 Judgment of 14 July 1972, ICI, C-48/69, EU:C:1972:70, para. 64.

18 Judgment of 8 July 1999, Hüls, C-199/92P, EU:C:1999:358, para. 161.

19 Jones and Sufrin (2016), p. 154.

20 Judment of 8 July 1999, Hüls, C-199/92P, EU:C:1999:358, para. 165.

21 Judment of 8 July 1999, Hüls, C-199/92P, EU:C:1999:358, para. 165.

22 Judgment of 7 January 2004, Aalborg Portland, C-204/00P, ECLI:EU:C:2004:6, para 81.

23 Schuchmann (2017), p. 106.

24 For more details see, for example, Jones and Sufrin (2016), p. 160.

25 The application of European competition law to oligopolistic markets is in detail discussed by Enchelmaier (1997); Schuchmann (2017).

26 Jones and Sufrin (2016), p. 161.

27 Judgment of 26 October 2000, Bayer, T-41/96, EU:T:2000:242, para. 71.
} 
explanation for such conduct might be that general changes in the market similarly affected all companies and led to an alignment of behavior.

For example, in oligopolistic markets ${ }^{28}$ supra-competitive price levels can be observed that could be the result of interdependent behavior and tacit collusion, which is not prohibited by Art. 101 TFEU. Rational and interdependent conduct of the undertakings can lead to parallel behavior which is often referred to as parallel behavior or tacit collusion and is not illegal under Art. 101 TFEU. Interdependency in an oligopoly cannot be equated with a concertation. ${ }^{29}$ Only under special certain instances can parallel behavior be forbidden as a misuse of market power according to Art. 102 TFEU. $^{30}$ The challenge of competition law in oligopolistic markets consists in identifying the demarcation line to what can be qualified as a forbidden concerted practice. Since tacit coordination - also referred to as tacit collusion and interdependent pricing - can also lead to supra-competitive prices, there has been some controversy as to whether the law on concerted practices should be changed in order to apply to this kind of conduct. An in-depth discussion on this issue is found in Sect. 5 below.

As an intermediate result, it can be noted that the existing provisions against price fixing do capture several but not all scenarios where the use of algorithms leads to a coordination of prices between competitors. However, several instances could be identified where the use of pricing algorithms results in a higher price level and therefore similarly harms consumers, but where the application of Art. 101 TFEU is difficult or disputed. At the core of these cases lies the discussion on the demarcation between forbidden tacit collusion on the one hand, and permissible independent parallel behaviour on the other hand. Drawing the borderline between these two scenarios constitutes one of the most complex tasks of competition law even if algorithms are not present.

Therefore, we first analyse in which economic scenarios tacit collusion can traditionally be observed (see below 4). Further, the strands of literature are discussed which seek to more adequately capture these scenarios through competition law (see below 5.1). We then show how the presence of algorithms widens the range of cases where a coordinated market outcome is facilitated, and in conclusion there is a discussion on which competition law measures might be taken in order to better address these cases (see below 5.2).

\section{Economic Prerequisites for Successful Collusion}

In a traditional context where no pricing algorithms are used by market participants, economic theory has identified oligopolistic markets as being particularly susceptible to tacit collusion. Under certain conditions in oligopolistic markets tacit collusion can lead to a market outcome with higher prices even if there are no explicit or implicit agreements between competitors.

\footnotetext{
28 The economics of oligopolistic markets are outlined below, see Sect. 4.

29 Van den Bergh (2017), p. 206.

30 See, for example, Schuchmann (2017), p. 120.
} 
Contrary to markets with perfect competition or to markets with a monopolist, the profits of an oligopolist are dependent on the actions chosen by the other competing oligopolists. ${ }^{31}$ A monopolist possesses the market power to maximize its profits by unilaterally limiting the market output and by setting the price above marginal costs. ${ }^{32}$ A monopolist will only extend its production as long as the additional revenue from this extension is higher than the cost of producing an additional item, which means that in the equilibrium the marginal revenues equal marginal cost. ${ }^{33}$ Under perfect competition a single firm is unable to obtain an impact on the market output and on the price and has to accept the price as a given parameter. $^{34}$ If a company raises its price in order to extend its profits, each competitor has an incentive to undercut the prices of its competitors in order to maximize its own profits. Thereby, competitive prices are reimposed. In the equilibrium the price equals marginal costs. ${ }^{35}$ Accordingly, price coordination between competitors is inherently unstable in a market with perfect competition.

In an oligopolistic market by contrast, the oligopolist is, under certain conditions, in a position to maximize its profit by taking into account the reaction of competing oligopolists. ${ }^{36}$ Strategic behavior in an oligopoly situation and its effects on the market and on welfare have been analyzed by a large volume of academic economic literature. The different strands of economic writing rely on different assumptions. ${ }^{37}$ They show that even absent a prior agreement, in oligopolistic markets prices can result in levels above marginal cost if certain conditions are met. ${ }^{38}$ The behavioral choices of a firm in an oligopolistic market and the interdependency with its rivals' decisions have, in particular, been analyzed through the application of game theory to oligopolistic markets. ${ }^{39}$ In particular, the prisoner's dilemma metaphor is used to illustrate the strategic choices of oligopolists and possible market outcomes. ${ }^{40}$ In the prisoner's dilemma scenario, two criminals who have committed a crime together are questioned independently. Neither prisoner can talk to the other before he testifies or remains silent or enters into a communication or into a binding commitment with the other prisoner. In terms of game theory this scenario is to be qualified as a non-cooperative game. ${ }^{41}$ Each prisoner is offered a lighter sentence if

\footnotetext{
31 Pindyck and Rubinfeld (2005), p. 474; van den Bergh (2017), p. 188.

32 Carlton and Perloff (2015), p. 113; Pindyck and Rubinfeld (2005), p. 342.

33 Carlton and Perloff (2015), p. 115; Pindyck and Rubinfeld (2005), p. 344.

34 Carlton and Perloff (2015), p. 85.

35 Pindyck and Rubinfeld (2015), p. 267.

${ }^{36}$ For a general overview about the economics in oligopolistic markets see, for example, Carlton and Perloff (2015), p. 181; Viscusi, Harrington and Vernon (2005), p. 101.

37 A short introduction to the seminal models by Cournot, Bertrand, Chamberlin and von Stackelberg can, for example, be found with Schuchmann (2017), p. 26; van den Bergh (2017), p. 188; Bishop and Walker (2010), 2-020; Pindyck and Rubinfeld (2005), p. 441; Carlton and Perloff (2015), p. 185.

38 Schuchmann (2017), p. 27.

39 An overview of the application of game theory to oligopostic markets is provided by Carlton and Perloff (2015), p. 183; Pindyck and Rubinfeld (2005), p. 473; van den Bergh (2017), p. 188; Hovenkamp (2016), § 4.2.

40 For the "prisoners' dilemma" see, for example, Pindyck and Rubinfeld (2005), p. 453.

41 Pindyck and Rubinfeld (2005), p. 474.
} 
he testifies against the other. With none of the prisoners testifying, the prosecutor's office can only impose a lighter sentence. From the prisoners' joint perspective the optimal outcome would be if both would not testify. However, from the individual perspective each prisoner runs the risk to incur a higher sentence if the other prisoner testifies. Game theory shows that in the equilibrium, both firms cheat. ${ }^{42}$ The Nash equilibrium - named after the economist John Nash - is defined as the state where, while taking into account the responses of the other player, no player has an incentive to change its behavior. ${ }^{43}$

The prisoner's dilemma model is applied to oligopolistic markets where the market players can choose between colluding and cheating with regard to their pricing strategy. ${ }^{44}$ If both firms collude, they would both maximize their profits. However, an individual firm can increase its individual profits by undercutting its competitors' prices and has to fear that its competitors are undercutting its price. In a one-period game without cooperation in the Nash equilibrium the competitors will seek to undercut each other's prices. To avoid this outcome the competitors would need to take measures in order to align their pricing behavior and to detect and avoid cheating.

The basic economic model of game theory that focuses on price coordination that is, Bertrand games - has been extended to multi-period games with infinite repetitions and has been further refined. In more detail, economic theory and empirical research have identified business strategies ${ }^{45}$ and market conditions where, even absent explicit collusion, price levels above competitive prices can be achieved in oligopolistic markets. ${ }^{46}$ For example, it has been shown that a "tit for tat strategy" where a player repeats the strategy of its competitor from the preceding round can lead to an evolution of cooperation. ${ }^{47}$ Quite similar effects can be observed when one enterprise follows the leadership strategy with regard to price or quantity ${ }^{48}$ or when a "trigger strategy" 49 is implemented. A "trigger strategy" means that a punishment is imposed upon a player who deviates from a supra-competitive pricing strategy in order to create an incentive for cooperative behavior.

Further, economic theory has identified conditions and market characteristics which favor the emergence of a supra-competitive price level in oligopolistic

\footnotetext{
$\overline{42}$ Van den Bergh (2017), p. 190; Schuchmann (2017), p. 33.

43 Viscusi, Harrington and Vernon (2005), p. 105; Bishop and Walker (2010), 2-020; van den Bergh (2017), p. 190.

44 Van den Bergh (2017), p. 190. When firms, on the other hand, coordinate quantity instead of price (i.e. in a Cournot game), the outcome in a single-shot game will be a supra-competitive price.

45 Practices to facilitate collusion are, for example, presented by Carlton and Perloff (2015), p. 403; Church and Ware (2000) p. 349.

46 Schuchmann (2017), p. 34; van den Bergh (2017), p. 190.

47 For further details on the "tit-for-tat-strategy" see, for example, Werden (2004), p. 733; Schuchmann (2017), p. 35 .

48 See, for example, Church and Ware (2000), p. 349; Schwalbe and Zimmer (2011), p. 47. With regard to the model by von Stackelberg: Bishop and Walker (2010), 2-031; Carlton and Perloff (2015), p. 200.

49 See, for example, Werden (2004), p. 733; Schuchmann (2017), p. 34.
} 
markets. ${ }^{50}$ At the outset there would have to be a coordination which does not consist in an implicit or explicit agreement. Further, for the coordination to be durable any deviation from the coordination needs to be detectable by the other market players and there needs to be a credible threat of a retaliation that outweighs the benefits of cheating. ${ }^{51}$ Among the most important (and interdependent) facilitating factors for these pre-conditions are market transparency, a low number of competitors, a high number of consumers, a high number of repeated interactions, stable demand and cost conditions, product homogeneity, ${ }^{52}$ and information ${ }^{53}$ exchanges. ${ }^{54}$ While facilitating practices can be taken as a point of reference for actually applying Art. 101 TFEU, facilitating factors can, in particular, be accounted for in a merger review where the competition authority has to make a prediction concerning the future development of the market. ${ }^{55}$ Refinements in modern economic theory have led to highly complex models which account for different strategies, market conditions and assumptions, and which allow for more realistic predictions of strategies and market outcomes. For example, in so-called supergames the players know the strategy of other players from previous rounds and can use this information in designing their future strategy. ${ }^{56}$ Also, it has been shown that multiple equilibria may exist and that asymmetric conditions - for example, with regard to different marginal costs of different market players or with regard to differences in quality, distribution channels or location - and product differentiation make collusion more difficult for the market participants because there is no focal price on which to coordinate. ${ }^{57}$ The example of asymmetries shows that an algorithm which perfectly determines the optimal price may come to a different result for different companies. In sum, competition economics in oligopolistic markets is one of the most unsettled and fast moving fields of economic research.

The use of AI-powered pricing software can have an impact on the conditions that facilitate collusion as described here. In Sect. 5, this paper will discuss whether this impact justifies a change in the law on anticompetitive agreements and concerted practices.

\footnotetext{
50 An overview is provided by Tirole (1988), p. 240; Schuchmann (2017), p. 40; van den Bergh (2017), p. 191.

51 Similar criteria need to be fulfilled for a cartel agreement to be stable. For a more detailed explanation see, for example, Bishop and Walker (2010), 5-017; van den Bergh (2017), p. 191.

52 On the other hand, under certain conditions, in a Bertrand game more product differentiation in an oligopolistic market moves prices towards monopoly levels; see, for example, Werden (2004), p. 723.

53 Information can refer to several relevant aspects like the demand curve, the strategies of other players, etc.

54 Information exchange can also be qualified as a facilitating practice; see, for example, Church and Ware (2000), p. 349. However, the possibility to (in)directly exchange information, e.g. through trade associations or through particular conditions in the business can also be analyzed as a factor that increases the likelihood of stable interdependent prices.

55 Schuchmann (2017), p. 41.

56 For supergames see, for example, Carlton and Perloff (2004), p. 204; Tirole (1988), p. 245.

57 Asymmetries are, for example, discussed by Tirole (1988), p. 240.
} 


\section{Should Tacit Coordination be Illegal Under Competition Law?}

To answer this question, as a starting point we first provide a broad sketch of the debate on oligopoly pricing that emerged decades before the emergence of AIpowered pricing algorithms. On this basis, we are able to identify if the latter phenomenon changes anything in the way of economic and legal implications that may or may not give rise to the need of changing EU law on tacit price coordination.

\subsection{The General Debate Over Interdependent Pricing}

For an analysis of the general issue, it is useful to start with the points where there is little disagreement among commentators and to later focus on those where there is greater debate. First, social harm does not differ whether the joint profit-maximizing price is achieved by overt communications or a tacit mutual understanding and there is no disagreement on this point. As Kaplow points out, the theory of repeated games - also called supergames - analyzes the structural requirements of a coordinated equilibrium "without regard to whether there was an old-fashioned cartel, pure interdependence, or some other manner of interaction or communication". 58

Another point of consensus is that of the perceived prevalence of mere interdependent behavior. Most scholars circumscribe this to a rare set of circumstances that include highly concentrated industries, homogeneous goods, symmetric cost structures across firms, and price transparency, among others. ${ }^{59}$ As will be seen in the next subsection, as the use of AI pricing software spreads, this may become less true.

The debate starts when setting the limits of the rule to punish oligopoly pricing. The positions range from restricting the prohibition to arrangements where communications between competitors have taken place to a broad rule that encompasses all kinds of coordinated pricing, even pure interdependence. In support of the former type of prohibition, Turner argues that consistency mandates that if monopoly pricing is not outlawed, then neither should mere interdependent pricing. ${ }^{60}$ Both are ways in which the winners reap the fruits of their luck or merit. In addition, and a point where many other commentators agree, ${ }^{61}$ an injunction on tacit price coordination would in practice establish a public utility type of regulation

\footnotetext{
58 Kaplow (2011a), p. 792. This is also why cartel theory is regarded as the basis for oligopoly theory. See Stigler (1964), p. 44; Carlton and Perloff (2015), pp. 151 and 181; Kaplow (2011b), p. 458 ("[both] extreme old-fashioned cartels (stripped only of their ability to legally enforce their agreements) and plain interdependence, along with everything in between, are analyzed as noncooperative games."). Noncooperative games is the strand of the literature that analyzes settings in which players are not able to conclude legally binding agreements, as is the case with price fixing.

59 Tirole (1988), pp. 240-242. Kaplow argues that there is little empirical evidence to support the assertion made by Kaysen and Turner that successful coordination is extremely likely even in moderately concentrated industries. Kaplow points to research on the structure-conduct-performance paradigm that suggests a low likelihood of mere interdependent pricing in highly concentrated markets. See Kaplow (2011b), p. 476 n. 46.

60 Turner (1962), p. 668.

61 Posner (2007), p. 303 and Posner (2004), p. 763.
} 
in which oligopolists are mandated to price at, or just slightly above, marginal cost. $^{62}$ Turner finds this impracticable because, among other reasons, marginal cost is either theoretically indeterminate - as in the case of joint products - or practically indeterminate. ${ }^{63}$ The author argues that "something more in the way of 'agreement' must be shown" with evidence of an actual agreement, prior understanding or at least prior communications. ${ }^{64}$

Page, also in support of a narrower prohibition, argues that a broader rule which focuses on mere interdependent behavior would yield too many false positives. According to the author, "[even] if rivals can achieve noncompetitive outcomes by purely tacit collusion, it does not follow that the law should condemn this conduct" because the administrability of rules limits the ability of the law to cover every instance of harm. ${ }^{65}$ Page puts forth a standard that covers something more than completed verbal agreements in which exchanges of mutual assurances have occurred. The author defines illicit concerted conduct as private communications, written or oral, in which competitive intention and reliance is disclosed. ${ }^{66}$ The rule does not require that firms mutually assure each other that they will keep the agreedupon prices, only that they privately disclose their intention to stick to a certain price and their decision to do so based on their reliance on what they expect their competitors to do. ${ }^{67}$ In addition, in order to reduce the probability of false positives, the proposed standard requires that the defendants act consistently with their statements. $^{68}$

Such a rule, according to the author, would be in accordance with economic theory because it would target the most stable forms of price agreements. ${ }^{69}$ In other words, Page argues that communications make oligopoly pricing more stable. This point is related to the fact that in a repeated Bertrand game, depending on the firms' discount rate of future profits, any price between the competitive and the monopoly

\footnotetext{
62 This appears to be Turner's strongest objection to a prohibition regarding pure interdependent behavior and not the need to allow oligopolists to reap monopoly profits. This can be illustrated by the fact that Turner does not object to a prohibition that covers parallel behavior in which all competitors charge only delivered prices, even if this was achieved only by pure interdependence. An injunction here could order the defendants to offer also f.o.b. and would therefore not require courts to become public utility regulators. However, this tacit coordinated practice is only a way in which oligopolists are rewarded. Nonetheless, Turner objects such rewards because they enhance the return that the oligopolist would otherwise obtain. See Turner (1962), p. 675.

63 Turner (1962), p. 670.

64 Id., p. 672.

65 Page (2012), p. 189.

66 Id., p. 184.

67 This formulation is, by itself, unclear. To illustrate his point, Page offers U.S. Steel Corp. [United States v. U.S. Steel Corp., 223 F. 55 (D.N.J. 1915) affirmed, 251 U.S. 417 (1920)] as an example of what he means as a communication of competitive intentions that differs from exchanges of mutual assurances. In what was referred to as the Gary Dinners, instead of concluding agreements on prices (because of a recognition of its illegality) the firms made declarations of the prices at which they were going to sell their products. It was implicit that these prices would be maintained and that in the event of a change, the firm in question should out of decency notify the rest of the producers. See Page (2012), p. 185, quoting U.S. Steel Corp. p. 174 (Woolley, J., concurring).

68 Id., p. 188.

69 Id., p. 190.
} 
one can be an equilibrium. ${ }^{70}$ Game theory does not formalize the role of communications - or make it one of its assumptions - when firms choose a price within this range. Kaplow argues that the problem of choosing a focal price can be solved by a process of tacit coordination. ${ }^{71}$ Page, for his part, argues that communications could play a role in eliminating the uncertainty over which the focal price will be chosen. ${ }^{72}$ His point is persuasive to the extent that the fact that the theory of supergames has little to say about communications can rather be seen as a weakness. The fact that in markets that could be considered ripe for tacit coordination there are instances where firms still risk liability and use overt communications is an indicator that oligopolists are not indifferent to their benefits. $^{73}$

With his proposed standard, Page attempts to give more concrete content to Turner's formulation that something in the way of an agreement needs to be proved. Whereas for the latter, the law should punish everything that is not pure interdependence, the former provides specific characteristics that the targeted behavior must show in order to be actionable under competition law.

Due to the greater concreteness of his proposed standard, Page is also able to give clearer guidance on how to apply it. The author does not insist on direct evidence of communications but proposes a method of indirect inference. Page suggests as a first approximation the existence of complex facilitating practices, which can only be achieved by overt communications and thus the existence of the former should be enough to infer the latter. ${ }^{74}$ If markets are prone to tacit coordination, then the marginal benefit of complex facilitating practices diminishes and firms would in theory avoid them due to the risk of liability. According to Page, the authorities should then focus on more competitively structured markets where firms have nevertheless been able to achieve a supra-competitive price. ${ }^{75}$ In such markets oligopolists may attempt to raise prices, but economic profits should be more

\footnotetext{
70 Based on this, Tirole remarks that in a way the theory of repeated games is "too successful in explaining tacit collusion" and that "the large set of equilibria is an embarrassment of riches." See Tirole (1988), p. 247.

71 According to the author, one of the firms could reason as follows: "Among the many equilibria available, I will choose one with supracompetitive prices, say, that with the monopoly price, because this will be mutually advantageous and accordingly I imagine that my competitors will reason likewise - and they will suppose that I am thinking this way, and so forth." See Kaplow (2011a), p. 796. See also Kühn and Vives (1995), p. 44 n. 12. To be fair, Kaplow does recognize that communications may play a role on aiding collusion but the theory underlying this intuition is still in an infant stage and communications do not unambiguously aid collusion. His point is, however, that communications are not necessary to form an agreement (understood as a meeting of the minds, which could include mere interdependent reasoning), and therefore a prohibition of the latter should not require the former. Id., section IV.B.2.

72 Page (2002), p. 190. See also Kaplow (2011a), n. 282 ("cheap talk is more widely regarded to be potentially useful in selecting among equilibria, each of which is, by definition, self-enforcing and thus compatible with parties' self-interest").

73 Connor (2007), p. 92.

74 Id., p.194.

75 There is an apparent contradiction between this point and Page's argument that his rule covers the most stable agreements. If one neglects industries that are conducive to coordinated behavior, one necessarily leaves out markets that on average have the most stable oligopoly prices. This inner tension in Page's work is due to the fact that he envisages a need to reconcile the objective of reducing social harm
} 
vulnerable to price cutting. If in such markets one is able to discern a pattern of oligopolistic pricing, then suspicion is warranted.

Under Page's standard, enforcers and courts would have to dismiss cases in which oligopolists have had limited success in raising prices in competitively structured markets but have not enhanced their capacity to do so with overt communications. Such false negatives, according to Page, should be tolerated since, as mentioned, the costs of administering a broader standard would outweigh its benefits.

Kaplow, on his part, sees things differently. He bases his opposition to a communications-based approach on an economic analysis of oligopoly pricing equilibrium, the effects of the conduct, and the relative merits of a broader rule that encompasses mere interdependence. Regarding equilibrium analysis, according to the author, game theory does not postulate that the steady-state price depends on whether firms have been able to communicate in a verbal or written manner. ${ }^{76}$ For theoretical purposes, such explicit exchanges could be considered cheap talk if the firms still have an incentive to deviate from the joint profit-maximizing price. Such incentives do not hinge on whether there have been private communications. ${ }^{77}$

The author argues that if one wants to ground the regulation on economics, then one should look at our current understanding of the theory of repeated games. ${ }^{78}$ As Kaplow points out, the theory requires only that the firms know their payoffs and the likely reactions of their competitors when deciding which strategy to pursue. Above-marginal-cost pricing can be an equilibrium if the firms realize that they gain more from sticking to the higher price or following a price hike. This depends on the conditions already described in Sect. 3 regarding the ability and incentives of oligopolists to detect and punish price cuts and the attitudes towards future profits. The theory of repeated games makes no mention of inter-firm communications and this is the reason why as a substantive matter Kaplow rejects the idea of a privatecommunications requirement.

In addition, regarding the analysis of the effects of the conduct, Kaplow also criticizes the argument that justifies oligopoly profits on the basis that antitrust law tolerates monopoly profits. According to him, the incentives of firms in an oligopoly setting to invest in product or cost-reducing innovations are weaker than in a monopoly or dominant firm setting because oligopoly profits depend to an extent on refraining from competing. In addition, such investments could make the firm more prone to defect from the joint profit-maximizing price if, for example, the decrease

\footnotetext{
Footnote 75 continued

with that of avoiding the punishment of mere interdependence. This, as will be explained below, is one of the dichotomies with which Kaplow takes greater issue.

76 Kaplow (2011a), p. 795.

77 Page points out that experimental economics suggests that talk, even when it is cheap, can increase the likelihood of collusive outcomes. See Page (2012), p. 191. Others, however, are more skeptical as to whether studies carried out with college students can actually reflect business realities. See Kaplow (2011b), p. 500; Haan et al. (2009) p. 21; Whinston (2006), p. 24.

78 Kaplow (2011a), p. 792.
} 
in costs is strong, which would increase the payoff of price cutting. ${ }^{79}$ If the expected oligopoly profits are high enough, firms will be discouraged from taking the risk of making cost-reducing investments.

As mentioned, Kaplow's objection to a narrower communications-based rule is not based on the social costs of oligopoly profits alone but also on the administrability of the standard. Common antitrust wisdom dictates that direct evidence of communications between executives should not be required because the fact that they are illegal provides the incentive to hide them. Therefore, inferences from a specific set of circumstances should be allowed. As Kaplow rightly points out, one of these circumstances is the existence of supra-competitive pricing. However, the communications-based prohibition requires that the inquiry does not stop there but also looks into factors that make an inference of mere interdependence less likely, which imposes additional litigation costs. ${ }^{80}$

Kaplow also takes issue with the implication that enforcement should focus only on industries that are not highly conducive to successful oligopolistic pricing. In his view, the rule would carve out that part of the economy where most of the harm is occurring. Furthermore, the risk of punishing genuinely competitive conduct in these markets is lower, so the risk of chilling effects is attenuated. Kaplow calls this the burden of proof paradox. To escape liability, defendants need to prove that the market in question is so conducive to collusion that their need to employ illegal forms of communication is diminished. That is, if there is enough evidence that the market is structurally non-competitive, then the conduct will be absolved. That could supply firms with the perverse incentive to employ communications in these circumstances since they expect, with a high probability, to be acquitted of wrongdoing. ${ }^{81}$

Another overlooked negative side of the communications-based approach, according to Kaplow, is that a definition of a set of illicit communications is inherently formalistic. This is because if one defines prohibited communications with a functional criterion - as opposed to a formal one - for example, as exchanges that enable successful collusion, then mere price signals would necessarily fall within the definition. ${ }^{82}$ Fixed definitions of what constitutes a prohibited form of communication are also problematic because of the high substitutability of forms of communication. ${ }^{83}$ An extreme example provided by Kaplow is that if what is prohibited is the private character of the exchange, then the only thing that firms need to do is to carry out a public press conference. Therefore, a formal definition of

\footnotetext{
79 Kaplow (2011b), p. 460. The author also points out other dynamic harms of oligopoly that apply in homogeneous goods (wasteful investment) and differentiated products settings (too little entry due to lack of appropriation of benefits of entrants). These harms, however, do not differ from those caused by monopoly and Kaplow does not argue that their intensity is greater in an oligopoly setting.

${ }^{80}$ Id., p. 491.

81 Id., p. 506.

82 Id., p. 482.

83 Ibid.
} 
what is deemed to be illegal price fixing impacts the effectiveness of the rule in attenuating the social problem of interest. ${ }^{84}$

Finally, Kaplow argues that the focus on the infeasibility of injunctions is misguided. These are, according to him, seldom used in cartel cases and with good reason. ${ }^{85}$ The only factor that deters firms from this kind of infringement is the expectation of punishment, not an order to cease profiting. In essence, Kaplow's argument is that fines solve the problem because they alter firms' payoffs. If the expected fine is high enough, then oligopolists will have a lower incentive to match a price increase or a higher incentive to break away from a supra-competitive price.

The problem with fines or damages awards is that, in order to achieve an optimal deterrence result, enforcers need information on marginal cost and the likelihood of detection. The discussion on how to establish the fine or damages usually does not take into consideration an important point. In most jurisdictions, fines do not exclude damages, which in the case of the US are trebled by the courts. The amount of money that firms end up paying for violating the law bears little relation to the actual harm they have caused. This can be justified with deterrence effects because firms do not have a probability of one of being caught. But what the probability actually is in each case or in the economy as a whole is obscure. The policy response to this uncertainty is therefore not necessarily an exact exercise.

Courts can use different standards of proof in the calculation of marginal cost and demand. Authorities in all jurisdictions have experience performing this analysis when deciding on damages and fines, which should be imposed in proportion to the social harm that has been established by the evidence. Judicial and administrative authorities could along these lines use estimates closer to the conservative one depending on their views on the costs of under and over-deterrence. In the worstcase scenario, some oligopoly profits could still be a general problem with a high burden of proof imposed on plaintiffs or prosecuting authorities. However, the problem would be alleviated to some extent because profits would be capped at a lower level from what would otherwise be the case without a rule that punishes mere interdependence. In addition, as will be seen in the next subsection, Big Data can in theory be harnessed by the public sector to refine predictions of marginal cost when it is not readily observable.

So, who offers the better solution? Kaplow admits that the question is an empirical one in which the prevalence of social harm under the various standards must be compared as well as their costs of administration. The problem is that a natural experiment in which a jurisdiction changes a narrow approach to a broad one is needed. Without such data, the only avenue available is to analyze what in theory are the relative merits of the competing standards in order to see if the predictions are unambiguous.

Regarding the prevalence of social harm, it is relatively straight forward that a rule with a broader sweep will tend to carry with it lower levels of the social harm it

\footnotetext{
${ }^{84}$ As will be analyzed in the next subsection, under certain circumstances it can be expected that artificial neural networks eliminate the need to conduct face-to-face meetings to eliminate uncertainty problems. This would be an extra argument to follow a more functional approach than a formalistic one. 85 Id., p. 475.
} 
addresses. This, however, has to be weighed against the effects that this greater scope of action can have on deterring socially desirable conduct. ${ }^{86}$ In this regard, although it may sound counterintuitive, it is not entirely clear whether mere interdependence is a socially undesirable conduct. As mentioned before, Kaplow argues that the dynamic incentives to invest in an oligopoly market may be weaker than those present in a monopoly setting. This, however, is not the only dynamic consideration of relevance. If there is no longer a place for oligopoly profits, what will the incentives be for oligopolists which are forced to price in a more competitive pattern? Price wars might be followed by attempts to consolidate the market in question. However, the strictness of merger control regimes may stand in the way. It appears unlikely that jurisdictions that adopt a strict standard against oligopoly pricing would be permissive of mergers to monopoly.

A related point is the effect on the contestability of monopoly markets. If a firm is considering entering a market with one firm, it knows it will have to compete even more fiercely since it is now fighting not just for a place in the market but for the place in the market. Uncertainty over the prospects of success will tend to discourage entry. The incumbent, on his part, risks more too and will therefore have an incentive to react even stronger to any kind of entry. Expecting an intensified reaction, the firm pondering entry will have additional reasons to refrain from doing so.

Incentives for entry might then be stronger for niche markets. On the flip side, dominant firms will have an additional incentive to occupy as many niches as possible in order to limit the market opportunities where future contestants could gain a foothold.

On the other hand, it is also possible that markets remain as oligopolies and that firms will not attempt to enter a winner-takes-all game. A normal profit might be inducement enough if the monopoly race is too costly. In addition, the incentives will depend on the standard to determine harm from oligopoly pricing. If damages or fines take into consideration that marginal cost is difficult to determine, then a reasonable approach is to set them conservatively. This would allow some margin of economic profits in oligopoly settings.

Where implementation of the standard is concerned, one could say that there is little room for discussion beyond remedies because it is not a point at which the proponents of a communications-based approach take aim. The main objections to a prohibition of mere interdependence outlined in this section have less to do with detectability and more with the unfeasibility of injunctions. Even Page's standard recognizes the need to have evidence on successful coordination, and therefore it is implied that his approach carries additional litigation costs with it. The author does say in passing that a broader rule that encompasses mere interdependence is impracticable, but fails to give reasons why the costs associated with it are too high.

With this outline of the decades-old debate on oligopoly pricing and with what has been explained on oligopoly theory in Sect. 4, we can now analyze the changes that machine learning and artificial neural networks bring to the debate. This analysis will be performed taking into consideration the framework used in the

$\overline{{ }^{86} \text { Kaplow (2011b), pp. } 508 \text { and }} 509$. 
literature covered in the present subsection, which focuses on social harm, costs of administering rules, and the incentives that the proposed standards put in place.

\subsection{What, if Anything, Changes with AI?}

A popular commercial application of AI has been predictive pricing. There are numerous firms that offer services for automating pricing decisions and many industries in which they have been used for a long time. To ask whether an analysis of the risks of $\mathrm{AI}$ is just fearmongering is a question that turns a blind eye to business realities. A more balanced approach requires taking into consideration both the benefits and the likely social costs that this technology brings to the pricing aspect of the market.

There are many industries where prices for the same good vary across several dimensions such as time of purchase and distribution outlet. Revenue management departments - which are in charge of optimizing prices in order to maximize revenue - are not so recent an invention. In the airline industry, American Airlines was the pioneer, whose approach was later copied by its competitors. ${ }^{87}$ One evident benefit from AI-powered pricing software is an increase in efficiency due to the lower costs of prediction made in these business units. Automation has reduced operational costs and improved performance in this area.

From the customer's perspective, predictive pricing can have some advantages as well. First, it reduces search costs. If a firm is able to make an accurate prediction on what the customer wants and is able to communicate this information, then he or she may benefit from this. ${ }^{88}$ Second, under certain conditions, predictive pricing may allow firms to serve more customer segments. Consumers may be better off with greater price dispersion. Third, AI can be more effective in differentiating passive from active consumers and may therefore allow competitors to compete more aggressively for non-loyal customers. ${ }^{89}$

There are, however, competitive risks associated with the use of AI in pricing decisions. This point is important for the purposes of the present paper because, as noted, many economists believe that pure interdependence (at least a stable form of it) is rare. If, according to what many commentators believe, algorithmic pricing will make this phenomenon more commonplace, then there might be a stronger case for a direct approach to oligopoly pricing instead of requiring communications to render the conduct illegal. On the other hand, even if the use of AI-powered pricing software makes social harm more acute, there are other problems related to the

\footnotetext{
87 Donovan (2005), p. 11.

${ }^{88}$ Ezrachi and Stucke, on the other hand, are concerned with consumer nudging that purchase suggestions may cause. See Ezrachi and Stucke (2017a), chapter 12. From a strictly allocative efficiency point of view, consumer nudging is not problematic because it just pushes the demand curve upwards. This, if anything, increases total welfare. Consumer nudging can, however, be problematic on other economic grounds such as income inequality and to the extent that it lowers the savings rate.

89 On the other hand, as Ezrachi and Stucke point out, the algorithm may also allow firms to better exploit sleepers and to offer the lowest discount needed to induce purchases from non-loyal customers and, thus, reduce the amount of profits that need to be given up to increase demand. See Ezrachi and Stucke (2017b), section I.v.
} 
administrability of a rule that outlaws tacit coordination aided by AI software. This subsection first considers the problem of social harm to then move on to an analysis of the administration costs of a broad rule that targets oligopoly pricing, focusing on the changes that AI brings. This subsection ends with an assessment of the incentives that a broad prohibition on interdependent pricing can put in place for firms considering whether to use this kind of software.

\subsubsection{Do Algorithms Enhance the Problem of Social Harm Caused by Oligopoly Pricing?}

The literature has identified some competitive risks arising from the use of artificial intelligence software that automates price decisions. First, price lags will tend to disappear since pricing software can react instantly to changes from competitors. ${ }^{90}$ Therefore, short-term gains from price cuts will decrease in markets where price information is transparent, such as in online retail.

Another way in which pricing software can stabilize price interdependence is by eliminating irrational reactions from firms. Price wars will be less likely to be triggered by arbitrary management decisions. As Ezrachi and Stucke put it, a computer does not respond in anger. ${ }^{91}$ In addition, as Mehra points out, one important aspect where irrational behavior plays a role in oligopoly equilibrium is the rate at which we humans discount future profits. According to the author, software would eliminate our inclination to hyper-discount and would therefore cause oligopoly profits to be more stable. ${ }^{92}$

Other than faster price responses and reduced irrationality, one overlooked risk from AI is its power to solve uncertainty. As discussed previously, coordinated supra-competitive pricing is in many settings difficult due to uncertainties regarding costs of competitors and other variables. If the algorithms can learn how to make accurate predictions on these points, then the need to solve these problems with face-to-face meetings may disappear. To be sure, the problem of achieving a tacitly coordinated equilibrium with the aid of artificial intelligence in the presence of firm asymmetries has already been pointed out by Gal. ${ }^{93}$ However, if one extends the logic of solving uncertainty to other areas, additional risks to consumer welfare can be identified, such as the lower likelihood of price wars when market conditions change.

One common source of equilibrium instability in oligopoly settings is said to be changes in demand. When, for example, a firm's demand drops, it may decrease its price in response. Other firms in the market may read this as an attempt to cheat on the profit-maximizing price and may react by punishing with marginal-cost pricing.

\footnotetext{
90 The decrease in time lags will be reduced both due to transparent market conditions and the speed at which algorithms can react. See Ezrachi and Stucke (2017a), chapter 7.

91 Ezrachi and Stucke (2017b), p. 5.

92 Mehra (2016), p. 1328. As was explained above, low impatience is a necessary condition for firms to break free from the competitive price trap in an infinitely repeated Bertrand game. If firms do not care for the future, the game turns de facto into a one-shot game, and the only equilibrium is the competitive price.

93 Gal (2018), pp. 13 and 14.
} 
On the other hand, if the other firms do suspect that there has been a change in demand of the price-cutting firm, they may adjust their prices so as not to lose much market share, e.g. by matching the price decrease of the first firm, but not necessarily to punish the deviating competitor by lowering the price to their marginal cost. Algorithms may learn to make accurate predictions in order to distinguish between the two scenarios and avoid unnecessary price wars.

Artificial neural networks can perform this task well if there is enough data. Machines are bad at predicting unusual scenarios for which there is not much past information. If there is a rich history of interactions between firms in the industry, then this condition may be fulfilled. Therefore, one factor that should be taken into consideration when assessing the feasibility of tacit coordination by algorithms is the availability of past data that can be used to make cost or demand inferences. This means that industry changes that are more radical, such as the introduction of new technologies, will still be able to destabilize cooperation. The machine will not be able to predict competitors' strategies with accuracy. ${ }^{94}$ On the other hand, under more routine settings, machines should do well in deciphering rival algorithms or at least in predicting their output. One example could be variations in demand due to prices of complements or substitutes that change often and for which therefore the companies have more information.

Another obstacle related to uncertainty and a tacitly-achieved joint-maximizing price is the problem of multiple equilibria in Bertrand supergames. As was explained in Sect. 5.1, if any price between marginal cost and the monopoly price can be an equilibrium when firms value future profits enough, then the problem remains of which price to choose. As already mentioned, overt communications may be necessary to solve this problem. However, and again under the assumption of a rich history of interactions, artificial neural networks could perform well in predicting their rivals' choices and therefore avoid the need for face-to-face communications.

Ittoo and Petit, on their part, cast doubt on whether certain machine-learning methods can actually achieve tacitly coordinated prices by themselves. They criticize the fact that a part of the literature uses some instances where algorithms have led to reduced consumer welfare by stabilizing oligopoly profits. For the authors, the literature has done nothing more than point out cases where tacit coordination was already likely and that algorithms may have "simply removed the last obstacle to it". 95 On the other hand, Ittoo and Petit do recognize that recent developments in the field of deep neural networks can indeed enable the interaction between pricing software leading to a supra-competitive equilibrium. ${ }^{96}$

What could settle the harm debate is empirical evidence. As mentioned at the beginning of the section, price optimization is a decades-old practice, so one could indeed measure the changes brought about by more recent advances in artificial

\footnotetext{
94 Another less extreme example could be the entry of new competition. The machine will need time to learn how the market will respond to the new rival. In the beginning, a price war may be inevitable. The problem is that artificial neural networks may reduce the time it takes for the price to stabilize.

95 Note that the authors do recognize that algorithms may have played a role but only question their significance in achieving the results described in the literature. See Ittoo and Petit (2017), p.2.

96 Ittoo and Petit (2017), p. 13.
} 
neural networks. The airline industry can be a good source. Itto and Petit point out that prices in this market have in fact been decreasing ever since the introduction of revenue management and that nothing has changed recently. ${ }^{97}$ However, the time trend of one variable can be regarded as a first approximation at best. Controlling for changes in demand and cost are necessary to isolate the effect of the introduction of AI pricing software.

The next empirical step could be to analyze a cross section of markets and test industry characteristics that may account for differences in the effects of the introduction of algorithmic pricing. The importance of this is based on the fact that experiments and simulations have established that algorithms compete fiercely in certain controlled games. ${ }^{98}$

Nonetheless, even with scant empirical evidence on the pervasiveness of the problem of social harm and how pricing algorithms have changed this, a reasonable approach could still be to devise a rule that in theory is able to discourage socially harmful uses of the technology in question without disincentivizing its welfareenhancing effects.

\subsubsection{Administrability of a Broad Prohibition on Interdependent Pricing}

A necessary condition to achieve a reduction in social harm without unduly encumbering the beneficial use of AI pricing software is a rule that is able to pinpoint with reasonable accuracy instances in which oligopoly pricing has led to economic profits. Regarding this issue, fast price responses from algorithms may make oligopoly pricing patterns look more similar to competitive behavior. In addition, the availability of data and increasing accuracy of predictions regarding market conditions may also enable firms to better coordinate their responses. If firms' prices are parallel and in response to market changes, it might be harder to distinguish instances of interdependent pricing from competitive interactions. One way in which Kaplow suggests that interdependent pricing can be identified is through sticky prices. ${ }^{99}$ Before the advent of AI-powered pricing software, coordinating changes was assumed to be costly. Therefore, in the presence of interdependent pricing one should have expected to see stickier prices that do not move according to changes in cost or demand. However, if algorithms can reduce information and coordination costs (by quickly predicting what the other competitors' price response to a change will be), then competitive and interdependent pricing patterns will tend to look the same.

In addition, faster price changes may make price signals harder to detect. An invitation to raise prices can last merely seconds and therefore would not appear on the radar unless this is the unit of time monitored by the antitrust authority. This situation should raise the cost of identifying instances of social harm.

Furthermore, calculating marginal cost has always been an Achilles' heel in antitrust discussions of pricing conduct. One thing is to be able to differentiate

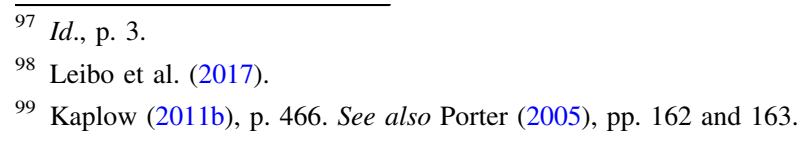


interdependent pricing patterns from competitive ones and another is to know how far from marginal cost the price is.

A possible solution has been proposed by Ezrachi and Stucke. The authors analyze the possibility of devising an algorithmic pricing incubator that the public authorities can use to make simulations and discern whether firms are pricing competitively or are capturing economic profits by reducing consumer welfare. ${ }^{100}$ If public authorities can indeed catch up with the use of the technology, then detection problems could be alleviated. There is no reason why, with enough data, the courts and enforcers would not be able to predict whether the price is close enough to the competitive benchmark. ${ }^{101}$ The latter could be established, for example, by simulating a game in which competitors take independent price decisions. In a setting with asymmetric firms, competitors need not agree (tacitly or expressly) on a joint-maximizing price to earn economic profits and it could therefore still be rational to require the algorithms to aim at a non-cooperative equilibrium.

Another issue related to detection that has become one of the central points of discussion is that artificial neural networks can be regarded as undecipherable black boxes due to the fact that their predictions are based on a myriad of variables combined in unintelligible ways. If that is true, then the issue of detection becomes more complicated since it will be harder to elucidate whether the software has set prices taking into consideration the likely reaction of competitors' algorithms. Regarding this point it is important again to consider business realities. If pricing software is indeed a black box, firms would be more reluctant to employ it because they have an incentive to know what drives the prediction in order to obtain better market insights. This is perhaps precisely why one of the main selling points on websites of firms that offer these software solutions is that they do not sell a black box. On the contrary, they assure that their users will know why the machine suggests a given price for a given segment.

\subsubsection{Incentives of Firms Under a Broad Prohibition of Interdependent Pricing}

The general incentives of a broad prohibition were covered in Sect. 5.1 when talking about the general debate regarding the law on oligopoly pricing. The present section focuses only on the incentives for the use of AI-powered algorithms in pricing decisions. The issue is whether, under a broad rule that outlaws mere interdependence, it will still be rational to automate pricing software with AI tools in order to realize their efficiency benefits.

The problem hinges not only on the analysis advanced in the previous subsection on detection but also on the remedy employed. In the case of fines and damages, both inquiries, as already pointed out, are intricately linked. Both analyses depend on an accurate calculation of marginal cost. If fines and damages are the preferred remedy choice, the incentives on the use of artificial neural networks will depend on their severity and whether the expected pecuniary liability changes because AI

\footnotetext{
$\overline{100}$ Ezrachi and Stucke (2017b), p. 51.

101 Use of econometric methods is standard practice in calculating damages. See McCrary and Rubinfeld (2014). Artificial neural networks could, with enough data, improve these prediction approaches.
} 
pricing software was being employed. If authorities consider the use of this technology as a plus factor or at the very least as an aspect to take into consideration when setting enforcement priorities, then there is a risk that interventions deter the use of AI pricing software even in instances where there has been no social harm.

As described in Sect. 5.1, a debate is ongoing concerning what the correct inference should be from industry characteristics that favor collusion. If these characteristics also make the adoption of pricing algorithms more likely (as, for example, price transparency or frequency with which the market accepts price changes), then the problem of over deterrence of the use of pricing algorithms could be enhanced.

If, as advanced in the previous subsection, governments can use artificial neural networks themselves to make an accurate prediction of the competitive benchmark, then this problem would be largely solved. Assuming then that the fine is calculated in the correct amount - a bold assumption since, as already pointed out, this also depends on an estimate regarding the likelihood of detection - artificial neural networks will still be used in pricing decisions to the extent that they confer other competitive advantages, such as better client segmentation or identifying variables associated with increases in revenue. ${ }^{102}$

At this point, it is important to note that to address tacit coordination by algorithms, some authors propose alternative competition law routes other than including them in a price-fixing prohibition. ${ }^{103}$ In this regard, Ezrachi and Stucke analyze other options because of the lacuna in the law on horizontal agreements but do not propose that provisions such as Sec. 1 of the Sherman Act should be read as to include mere interdependence achieved by pricing software. In any case, such intervention tools still result (in some jurisdictions) in the use of structural and behavioral remedies and, therefore, the discussion of their suitability to solve the problem is similar to that in the context of the law on price fixing. With that in mind, some of the methods that Ezrachi and Stucke propose - and which can be viewed as remedies - are the following: (1) reducing the frequency of price changes in order to make price cuts more profitable, (2) reducing price transparency for the algorithms but not for consumers, and (3) testing whether market structure influences the ability to collude (relevant for merger review). The authors suggest that these measures could be tested in the algorithmic pricing incubator that they propose. ${ }^{104}$

Mehra, on his part, argues that since the use of algorithms carries its own benefits, ${ }^{105}$ a per se rule would be ill fitted to approach the problem. On the other

\footnotetext{
${ }^{102}$ These competitive advantages may have other antitrust implications themselves, especially in jurisdictions were exploitative unilateral conduct can be targeted by antitrust authorities. However, this analysis lies outside the scope of the present paper.

103 One exception is Gal, who also proposes to widen the net of current price-fixing prohibitions to deal with algorithmic tacit collusion. See Gal (2018), pp. 43 and 44.

${ }^{104}$ Ezrachi and Stucke (2017b), Part II.

105 Mehra points out benefits from the use of algorithms in areas other than pricing. It is important to stress that when analyzing a case on algorithmic pricing the authorities should focus only on the benefits of the pricing software and not on the benefits of artificial intelligence in general in the market. The reason is that a rule that addresses only the pricing aspect will not have an effect in the adoption of artificial intelligence in other business areas. Therefore, the benefits in these other aspects should not enter into the balancing analysis.
} 
hand, because of the same benefits, the author also concludes that a rule-of-reason analysis would not be appropriate either. Although Mehra has a point regarding the lack of merits of a blanket prohibition, his argument on the non-suitability of a ruleof-reason approach does not take into consideration that such a rule originated precisely due to the need for carrying out a balancing of tradeoffs when the net effect of a conduct is not a priori clear. The author's argument may be grounded on the fact that such balancing is in practice not particularly manageable when direct evidence on effects is not at hand (and as a consequence the authorities are required to perform a qualitative analysis and make a subjective judgement on whether the benefits compensate the harm). Mehra therefore argues that the best approach may be a "proactive shaping of industry behavior through dialogue with stakeholders, targeted regulation, and/or norm generation" - in other words, a combination of regulation and competition advocacy programs such as the ones used by the FTC when addressing consumer privacy issues. ${ }^{106}$

Another valid question is whether the market can take care of the problem more efficiently than public interventions. In this respect Gal and Elkin-Koren argue that the use of $\mathrm{AI}$ on the demand side to aid consumption decisions may develop as a counterbalance to market power that may be enhanced by algorithmic pricing on the supply side. Not only that, but algorithmic consumers - that is, software that automates purchasing decisions - can introduce parameters aimed at destabilizing oligopolistic market structures and even detect cartels. ${ }^{107}$

However, as Gal herself admits, algorithmic consumers are only a partial solution. ${ }^{108}$ The author points to the following limitations of digital butlers: (1) they can also enter into illegal agreements or abuse their market power, (2) suppliers of consumer algorithms may be dominated by firms that may not have the consumers' best interests at heart, and (3) the supply can take countermeasures to algorithmic consumers. ${ }^{109}$ In addition, algorithmic consumers may not reach many markets were consumers do not behave according to the neoclassic passive consumer model. In markets where consumers are more active or preferences are not fixed, algorithmic consumers might never become widespread. As Gal and Elkin-Koren recognize, we humans may never be willing to rely on algorithms to make jewelry purchasing decisions. ${ }^{110}$

The point of bringing up these alternative proposals is to highlight that a discussion of remedies should not be undertaken in isolation of the relative merits of other competition policy responses that are available. Market inquiries and proactive regulatory and advocacy programs could either co-exist or exclude anticompetitive behavior prosecution. Should the authorities choose to expand the

\footnotetext{
106 Mehra (2016), p. 1371.

107 Gal and Elkin-Koren (2017), pp. 328-331.

108 Gal (2018), p. 23.

109 Id., p. 25.

${ }^{110} \mathrm{Gal}$ and Elkin-Koren (2017), p. 318. On the other hand, algorithmic consumers may have other limitations that could hinder their adoption even in markets like grocery shopping. The value of autonomy may not depend on the goods in question since it can touch on sensitive topics (to what extent are we willing to let machines take over).
} 
interpretation of what an illegal agreement between competitors is and cover mere interdependence, the issue remains as to what parts of the toolkit authorities should draw from in order to achieve better results.

Market inquiries that, in some jurisdictions, can result in behavioral and structural remedies may not be a better solution than the prosecution of anticompetitive behavior. This will depend on the standard of proof that authorities bear in order to justify a given measure, e.g. limiting price transparency. In addition, as has been seen, one of the best options to deter anticompetitive behavior may be fines and damages that alter the payoffs of the firms. This measure can be imposed only when a violation of the law is found.

Before the advent of artificial neural networks, the discussion centered around the infeasibility of remedies and the irrationality of an order to make price decisions without regard to competitors' reactions. Structural remedies have not been discussed and behavioral remedies only regarding conduct that involves facilitating practices. With AI algorithms new options appear that should be addressed. For example, one remedy option could involve how the algorithm is programmed. An injunction would be on clearer terms if it addresses specific aspects of the code. Authorities could order firms to program their algorithms so as to play competitive instead of cooperative games. Simulations carried out in algorithmic incubators of the kind proposed by Ezrachi and Stucke could in theory be used to police the type of game being played. The key to solving the legal dilemmas surrounding algorithmic tacit coordination rests heavily on the issue of remedies and should therefore receive increasing attention in the academic debate.

\section{Conclusions}

Taking into account the nature of artificial neural networks, it is indeed likely that their use can expand the settings under which a joint-maximizing price can be set without the need of resorting to overt communications. In addition to the risks commonly described in the literature, these circumstances are those in which there is enough market data that the algorithms can use to make accurate predictions on competitors' costs, the cause of price changes (which could be either attempts to cheat or a response to changes in the market), and finding a focal price among a wide array of options.

The problem of detection is also altered. Faster price responses to market changes will make it more difficult to distinguish between competitive behavior and interdependent price patterns (which before the advent of artificial neural networks were assumed to be less responsive to changes in cost and demand). On the other hand, if governments can themselves harness the power of AI, they could accurately estimate the competitive benchmark and thus detect how much the market price deviates from it.

The problem of the black box is, at least in this application of AI technology, not so acute. Firms that offer AI-powered pricing software solutions have developed their products so as to make the predictions transparent. This is because of the fact that the users of the software value the market insights they can derive from the prediction. 
Regarding the incentive for firms of a broad prohibition, one element that does not change with artificial neural networks is the fact that a race to monopoly may be fostered. One could argue that such a race is desirable but what is worrying is the long-term trend. Once a monopoly is achieved, it will (all else constant) tend to be more stable due to the incentives put in place by a broad prohibition that covers tacit coordination. This problem will not be so severe in asymmetric conditions. Firms with differentiated products and production technologies will still be able to reap economic profits without the need of aiming at a cooperative equilibrium.

Finally, one of the issues that will significantly determine whether a broad prohibition on price fixing is workable is that of remedies. Its analysis has received some attention in the literature but more work needs to be done in the following areas: What are the relative merits of the different competition policy responses that could be available (fines, damages, behavioral and structural orders, regulation, and advocacy efforts)? How should they be used in the face of other market autocorrection mechanisms such as algorithmic consumers? Are remedies aimed at the programing of the pricing software feasible? These questions are the subject of a work in progress by the authors of the present contribution.

Acknowledgement Open access funding provided by the Max Planck Society.

Open Access This article is distributed under the terms of the Creative Commons Attribution 4.0 International License (http://creativecommons.org/licenses/by/4.0/), which permits unrestricted use, distribution, and reproduction in any medium, provided you give appropriate credit to the original author(s) and the source, provide a link to the Creative Commons license, and indicate if changes were made.

\section{References}

Agrawal A, Gans J, Goldfarb A (2018) Prediction machines: the simple economics of artificial intelligence. Harvard Business Review Press, Brighton

Alpaydim E (2014) Introduction to machine learning. The MIT Press, Cambridge

Bishop S, Walker M (2010) The economics of EC competition law. Sweet \& Maxwell, London

Carlton D, Perloff J (2004) Modern industrial organization. Pearson Education Limited

Carlton D, Perloff J (2015) Modern industrial organization. Pearson, Essex

Church J, Ware R (2000) Industrial organization: a strategic approach. McGraw-Hill, Boston

Connor J (2007) Price fixing overcharges: legal and economic evidence. In: Zerbe R, Kirkwood J (eds)

Research in law and economics, vol 22. Emerald, Bingley, pp 59-153

Donovan A (2005) Yield management in the airline industry. J Aviat/Aerosp Educ Res 14:11-19

Enchelmaier S (1997) Europäische Wettbewerbspolitik im Oligopol. Nomos, Baden Baden

Ezrachi A, Stcke M (2017a) Two artificial neural networks meet in an online pub and change the future (of competition, market dynamics and society). The University of Tennessee Knoxville, College of Law Research Paper Series. http://dx.doi.org/10.2139/ssrn.2949434. Accessed 30 Nov 2018

Ezrachi A, Stucke M (2017) Virtual competition. Harvard University Press, Cambridge

Gal M (2018) Algorithms as illegal agreements. Berkeley Technol Law J (forthcoming)

Gal M, Elkin-Koren N (2017) Algorithmic consumers. Harvard J Law Technol 30:309-354

Haan M, Schoonbeek L, Winkel B (2009) Experimental results on collusion. In: Hinloopen J, Norman H (eds) Experiments and competition policy. Cambridge University Press, Cambridge, pp 9-33

Hovenkamp H (2016) Federal Antitrust policy - the law of competition and its practice. WEST, St. Paul, MN, United States 
Ittoo A, Petit N (2017) Algorithmic pricing agents and tacit collusion: A technological perspective. http:// dx.doi.org/10.2139/ssrn.3046405. Accessed 30 Nov 2018

Jones A, Sufrin B (2016) EU competition law. Oxford University Press, Oxford

Kaplow L (2011a) On the meaning of horizontal agreements in competition law. Calif Law Rev 99:683-818

Kaplow L (2011b) Direct versus communications-based prohibitions on price fixing. J Legal Anal 3:449-538

Kühn K, Vives X (1995) Information exchanges among firms and their impact on competition. Report to the European Commission

Leibo et al. (2017) Multi-agent reinforcement learning in sequential social dilemmas. In: Proceedings of the 16th international conference on autonomous agents and multi-agent systems. https://storage. googleapis.com/deepmind-media/papers/multi-agent-rl-in-ssd.pdf. Accessed 30 Nov 2018

McCrary J, Rubinfeld D (2014) Measuring benchmark damages in antitrust litigation. J Econom Methods 3:63-74

Mehra S (2016) Antitrust and the robo-seller: competition in the time of algorithms. Minn L Rev 100:1323-1376

Neapolitan R, Naimipour K (2010) Foundations of algorithms. Jones \& Bartlett Learning, Burlington

Page W (2012) A neo-Chicago approach to concerted action. Antitrust Law J 78:173-200

Pindyck R, Rubinfeld D (2005) Microeconomics. Pearson Prentice Hall, Upper Saddle River

Porter R (2005) Detecting collusion. Rev Ind Organ 26:147-167

Posner R (2007) Economic analysis of law. Wolters Kluwer, Alphen aan den Rijn

Posner R (2014) Review of Kaplow, “competition policy and price fixing”. Antitrust Law J 79:761-768

Priddy K, Keller P (2005) Artificial neural networks: an introduction. SPIE press, Washington

Schuchmann F (2017) Die Behandlung von tacit collusion im europäischen und deutschen Kartellrecht. Nomos, Baden Baden

Schwalbe U, Zimmer D (2011) Kartellrecht und Ökonomie. Verlag Recht und Wirtschaft, Frankfurt am Main

Stigler G (1964) A theory of oligopoly. J Polit Econ 72:44-61

Tirole J (1988) The theory of industrial organization. The MIT Press, Cambridge

Turner D (1962) The definition of agreement under the Sherman Act: conscious parallelism and refusals to deal. Harvard Law Rev 75:655-706

van den Bergh R (2017) Comparative competition law and economics. Edward Elgar, Cheltenham

Viscusi K, Harrington J, Vernon J (2005) Economics of regulation and antitrust. The MIT Press, Cambridge

Werden G (2004) Economic evidence of the existence of collusion: reconciling antitrust law with oligopoly theory. Antitrust Law J 71:718-800

Whinston M (2006) Lectures on antitrust economics. The MIT Press, Cambridge 